\title{
CÓMO CRIAR Y EDUCAR A UN NIÑO CON NECESIDADES EDUCATIVAS ESPECIALES
}

\author{
Dra. Bertha E. Martínez Ocaña \\ Docente de la Escuela Profesionald de Ecudación
}

\section{Cuando los padres se enteran que sus hijos tienen una discapacidad}

La familia es la comunidad social básica más natural y necesaria; en ella deben darse en grado muy especial, todos aquellos valores fundamentales; esto es comunicación, diálogo, autodeterminación, colaboración y amor.

La principal misión de la familia es contribuir a la formación de la persona, comenzando por los propios cónyuges y continuando con los hijos. En ello el ser humano se hace más persona y adquiere un elemento indispensable para formar su carácter, valerse por sí mismo y asumir sus responsabilidades. La familia es el ente socializador por excelencia y el ambiente propicio para crecer plenamente como persona.

Los padres son los que mejor conocen y los más interesados en ayudar a sus hijos. Cuando los padres de familia llegan a saber que su niño tiene una discapacidad, comienza una jornada en su vida que muy a menudo está llena de emociones fuertes, alternativas difíciles e interacciones con profesionales y especialistas diferentes y sienten la necesidad continua de información y servicios. Muchos padres manifiestan que al enterarse del diagnóstico sobre su hijo, esto les llega como un golpe fuerte. Algunas madres sienten que ante esta noticia sienten como si se le hubiera arrojado en la cabeza un saco negro obstruyendo su habilidad de escuchar, ver y pensar en forma normal.

Al comienzo, los padres se pueden sentir aislados y solos, y puede ser que no sepan dónde buscar ayuda, información y apoyo. Este artículo pretende ser un mensaje de apoyo y un punto de partida a las necesidades de información de aquellos padres que se han enterado que su niño tiene necesidades educativas especiales. He creído conveniente adaptar el artículo: Ud. no está solo, de Patricia McGill Smith. Ella escribe desde una perspectiva personal de una madre que ha compartido esta experiencia y todo lo que va con ella. 
Estas descripciones pudieran parecer un poco dramáticas, pero ellas nos describen suficientemente las emociones múltiples que inundan las mentes y los corazones de los padres cuando reciben alguna mala noticia acerca de sus hijos.

\section{Reacciones comunes}

Los padres pasan por una secuencia general de estados emocionales que se experimentan típicamente y manifiestan: choque, negación, miedo, culpabilidad, confusión, falta de poder, desilusión, rechazo y aceptación.

Una primera reacción, los expertos las denominan choque, se trata de sentimientos de indiferencia en las que los padres escuchan las palabras, saben lo que quieren decir, pero en realidad no sienten nada, es como si se sintieran flotando.

Otra reacción que experimenten es negar que existe un problema. Esto no puede estar sucediéndome a mí, a mi hijo, a nuestra familia. Manifiestan que su hijo está cansado o que es su manera de ser ya se le pasará, son manifestaciones de escape cuando no quieren aceptar que su hijo tiene una discapacidad.

La negación rápidamente se fusiona con el enojo, el cual puede ser dirigido hacia el profesional que le proporcionó la información acerca del problema de su hijo. El enojo puede afectar la comunicación entre esposos o con los abuelos u otros miembros queridos de la familia.

El miedo, es otra respuesta inmediata. A menudo se siente temer a lo desconocido más que a lo conocido. El miedo al futuro es una emoción entre los padres de estos niños. Se preguntan: ¿Que va a suceder a este niño cuando tenga cinco años de edad, cuando tenga doce años de edad, cuando tenga veintiún años de edad? ¿Qué va a suceder a este niño cuando yo no exista? ¿Aprenderá algún día? ¿Tendrá la capacidad de amar, vivir, reírse, y hacer todas las cosas que teníamos planificadas? Otros asuntos desconocidos también les inspiran miedo. Los padres temen que la condición del niño sea peor de lo que pudiera ser.

Existe en ellos el miedo al rechazo a la sociedad, miedo acerca de cómo los hermanos y hermanas serán afectados. Estos temores casi pueden paralizar a algunos padres.

La culpabilidad, es otro sentimiento que manifiestan los padres e impide tomar las decisiones necesarias. La culpabilidad y la preocupación acerca de si los mismos padres han causado el problema: iHice alguna cosa para causar esto? ¿Estoy siendo castigado por algo que hice? ¿Acaso mi esposa no se cuidó debidamente cuando estuvo embarazada? O la niña se cayó cuando era muy pequeña y se golpeó la cabeza, o quizá uno de los hermanos o hermanas inadvertidamente la dejaron caer y no dijeron nada. Muchos sentimientos de reproche y remordimiento pueden derivarse al tratar de encontrar las causas de la discapacidad. 
Al respecto Diamond, S. (1997) portavoz elocuente de las necesidades de los minusválidos manifiesta:

Mi madre hizo las leyes de la disciplina. Mi padre siempre me llevaba a una nueva aventura, ayudándome a ver, oír y saborear la vida. Mi madre, siempre introspectiva; a la edad de los 70 años me habló de los sentimientos de culpabilidad que tiene un padre de familia, de una niña discapacitada bajo su cuidado. Dijo que por primera vez en su propia vida entendió su culpabilidad personal. No una culpabilidad por haber hecho algo mal o por tener una niña discapacitada, pero una culpabilidad por no haber hecho lo mejor por su hija. Utilizó ejemplos: pudiera haber buscado a otros doctores para obtener mejor ayuda para mí, sentir que pudiera haber explorado otros tratamientos de terapia y sentir que pudiera haber suavizado más el dolor a que fui expuesta yo porque estaba inhabilitada (p. 28).

Sentimientos de culpabilidad también pueden ser manifestados en interpretaciones espirituales y religiosas de reproche y castigo. Ellos gritan, ¿Por qué Yo?, o ¿Por qué a mi niño?, muchos padres también dicen, ¿Por qué Dios me ha hecho esto a mí? Levantan los ojos al cielo y preguntan: ¿Qué es lo que he hecho para merecer esto?

En este periodo traumático muchas cosas se pueden hacer para ayudarse a sí mismo.

La confusión también marca este período traumático; y se manifiesta a través de la pérdida de sueño, la inhabilidad para tomar decisiones y una sobrecarga mental.

En medio de este trauma, la información puede parecer alterada y distorsionada. Los padres escuchan palabras nuevas que nunca escucharon, términos que no pueden entender, quieren saber qué significa todo esto; y sin embargo pareciera que no pueden encontrar sentido a toda la información que el profesional está tratando de comunicar acerca de la discapacidad de su niño.

La falta de poder para cambiar lo que está sucediendo es muy difícil de aceptar. En efecto, ellos no pueden cambiar el hecho de que su niño tenga una discapacidad, y sin embargo, los padres quieren sentirse competentes y capaces de manejar las situaciones de su propia vida. Es extremadamente difícil ser obligados a depender de juicios, opiniones y recomendaciones de otros, estas son generalmente personas extrañas con las cuales no existe ninguna confianza establecida.

La desilusión de tener un niño que no es perfecto presenta un reto al orgullo de muchos padres y desafío a su sistema de valores. Esta sacudida a sus expectativas previas puede crear una resistencia a aceptar al niño como una persona de valor en desarrollo. 
El rechazo es otra reacción que experimentan muchos padres. El rechazo puede ser dirigido hacia el niño o hacia el personal médico o hacia otros miembros de la familia.

Durante este periodo de tiempo cuando muchos sentimientos diferentes pueden inundar la mente y el corazón, no hay forma de medir cuan intensamente un padre puede experimentar esta constelación de emociones. No todos los padres pasan a través de estas etapas, pero es muy importante para ellos identificarse con todos los sentimientos potencialmente penosos que pueden presentarse, de modo que sepan que ellos no están solos. Hay muchas acciones constructivas que pueden tomarse inmediatamente, $y$ hay muchas fuentes de ayuda, comunicación y seguridad renovada.

Patricia McGill Smith, sugiere algunas acciones que pueden ser seguidas por los padres que tiene un hijo discapacitado.

\section{- Busque la asistencia de otro padre}

Hubo un padre que la ayudó. Veintidós horas después del diagnóstico que le dieran sobre su hija, el hizo una afirmación que nunca ha olvidado: Puede ser que usted no lo reconozca hoy, pero va a llegar el momento en su vida en que se dará cuenta que tener una hija con una discapacidad es una bendición. Puede recordar sentirse confundida por estas palabras, las cuales fueron ni más ni menos un regalo, muy valioso que encendía la primera luz de esperanza para ella. Este padre habló de esperanza para el futuro. Le aseguró que habían programas, que habría progreso, y que habría ayuda en muchas formas y de muchas fuentes. Él era padre de un niño con retraso mental.

En muchos lugares de Lima y del Perú, existen, instituciones que orientan y brindan ayuda a los padres de niños discapacitados: ADM PERÚ (Asociación de Distrofia muscular del Perú), ASPAU (Asociación de Padres y Amigos de Personas con Autismo), ASD (Asociación de Sordos del Perú), Sociedad Peruana de Síndrome de Down, (Estos centros y otros se pueden descubrir en el Directorio de Sociedad y Discapacidad del 2000).

Mi primera recomendación es tratar de encontrar otro padre de un niño con una discapacidad similar, preferentemente uno que ha elegido ser ayudante de padres, y pedir su asistencia y orientación.

- Hable con su cónyuge, familia y otros seres queridos

A través de los años he descubierto que muchos padres no comunican sus sentimientos relacionados a los problemas que tienen sus niños. El esposo a menudo está preocupado por ser una fuente de apoyo para su cónyuge. Mientras más comunicación puedan tener en momentos difíciles como estos, mayor será 
su fuerza colectiva. Entienda que cada uno de ustedes enfoca su rol de padre en forma diferente. Puede ser que se sientan y respondan a este desafío nuevo de distintas maneras. Traten de explicarse a cada uno cómo se siente. Traten de entenderse cuando no vean las cosas del mismo modo.

Si hay otros niños, hablen también con ellos. Estén alerta sobre sus necesidades. Si ustedes no se encuentran emocionalmente capaces de hablar con sus niños o cuidar de sus necesidades emocionales en este momento, identifiquen otros miembros dentro de la estructura de la familia quienes puedan establecer un vínculo comunicativo especial con ellos. Hablen con otras personas importantes en su vida, sus mejores amigos, sus propios padres. Para mucha gente, la tentación de cerrarse emocionalmente en este momento es grande, pero puede ser tan beneficioso tener amigos de confianza y parientes que pueden ayudarles a llevar la carga emocional que sienten.

\section{- Confíe en fuentes positivas en su vida}

Una fuente positiva de apoyo y sabiduría puede ser su párroco o sacerdote. Otra puede ser un buen amigo o consejero. Acérquese a aquéllos que antes hayan sido un apoyo en su vida. Encuentre los recursos nuevos que usted necesita ahora. Un consejero muy bueno una vez me dio una receta para vivir a través de una crisis: "Cada mañana, cuando se levante, reconozca su falta de poder para controlar la situación que tienen entre manos, entregue este problema a Dios, y comience su día". Cuando perciba que sus sentimientos sean dolorosos, usted deberá hacer el esfuerzo y contactar a alguien. Llame o escriba o tome su vehículo y comuníquese con una persona real que hablará con usted y participará de su dolor. El dolor dividido no es tan difícil de llevar como el dolor en aislamiento. A veces el consejo profesional se hace necesario; si piensa que esto puede ayudarle, no sea reacio y busque esta asistencia.

\section{- Viva un día a la vez}

El miedo al futuro nos puede inmovilizar. El vivir con la realidad del día presente se hace más manejable si disipamos las preguntas de ¿qué?, ¿sí? y entonces, ¿qué? en el futuro. Aunque no parezca posible, cosas buenas continuarán sucediendo cada día. Inquietarse acerca del futuro solamente agotará sus recursos limitados, usted tiene suficiente de que preocuparse.

\section{- Aprenda la terminología}

Cuando usted se enfrente a una terminología nueva, no vacile en preguntar qué es lo que significa. Cuando alguien use una palabra que usted no entiende, detenga la conversación por un minuto y pida a la persona que le explique su significado. 


\section{- Busque información}

Algunos padres virtualmente buscan toneladas de información; otros no son tan persistentes. Lo importante es que requiera información exacta. No tenga temor de hacer preguntas, porque haciendo preguntas será su primer paso para comenzar a entender más acerca de su niño. Aprender cómo formular preguntas es un arte que hará su vida mucho más fácil para usted en el futuro. Un método aconsejable es escribir sus preguntas antes de asistir a una sesión o reunión y escribir más preguntas al tiempo que las piensa durante la reunión. Obtenga fotocopias de toda la documentación relacionada a su niño la cual mantienen los médicos, psicólogos, maestros y terapeutas. Es aconsejable utilizar un archivador en el cual juntar toda la información que le sea dada. En el futuro tendrá necesidad de utilizar esa información que ha recopilado y archivado, manténgala en un lugar seguro. De nuevo, siempre recuerde de pedir copias de las evaluaciones, reportes de diagnósticos, y reportes de progreso. Si usted no es una persona naturalmente organizada, simplemente tome una caja y lance todos los papeles de trabajo en ella. Entonces, cuando realmente la necesite, estará allí.

\section{- No se sienta intimidado}

Muchos padres se sienten incómodos ante la presencia de médicos, psicólogos o profesores debido a sus credenciales $y$, a veces, debido a sus modales profesionales. No se sienta intimidado por los antecedentes educacionales de éstos y otro personal que puedan estar involucrados en tratar o ayudar a su niño usted no debe dar explicaciones por querer saber lo que está ocurriendo. No se preocupe de ser quien esté molestando o haciendo muchas preguntas. Recuerde, éste es un niño, y esta situación tiene un efecto profundo en su vida y en el futuro de él. Por lo tanto, es muy importante que sepa todo lo que pueda acerca de su situación.

\section{- No tenga temor de mostrar emociones}

La mayoría de padres de familia, especialmente los papás, reprimen sus emociones porque creen que el dar a conocer a las personas como se están sintiendo es un signo de debilidad. Los padres más fuertes de niños con discapacidades a quienes yo conozco no tienen temor de mostrar sus emociones. Ellos entienden que al revelar sus sentimientos no disminuye su fortaleza.

\section{- Aprenda a tratar con los sentimientos naturales de enojo y amargura}

Los sentimientos de enojo y amargura son inevitables cuando usted se da cuenta de que deberá revisar los sueños y esperanzas que originalmente tenía para su niño. Es muy valioso reconocer su enojo y aprender a alejarse de él. Puede ser que necesite ayuda ajena para poder hacer esto. Puede ser que no se sienta como 
tal, pero la vida mejorará y llegará el día en que se sentirá positivo de nuevo. Por medio de reconocer y trabajar a través de sus sentimientos negativos, usted estará mejor equipado para enfrentar desafíos nuevos, el enojo y la amargura nunca más habrán de agotar sus energías e iniciativa.

\section{- Mantenga un aspecto positivo}

Una actitud positiva será una de sus herramientas más valiosas para tratar con los problemas. Siempre hay, un lado positivo de cualquier cosa que está ocurriendo. Por ejemplo, cuando se descubrió que su niña tenía una discapacidad, una de las otras cosas señaladas fue que ella era una niña muy sana. Aún lo es. El hecho de que ella no ha tenido impedimentos físicos a través de los años ha sido una bendición grande; ella ha sido la más sana de todos los niños que ha criado. Concentrarse en los aspectos positivos disminuye los negativos y hace más fácil enfrentarse con la vida.

- Manténganse en contacto con la realidad

Mantenerse en contacto con la realidad es aceptar la vida en la forma que es. Mantenerse en contacto con la realidad también es reconocer que hay algunas cosas que nosotros podemos cambiar y otras cosas que no podemos cambiar. La tarea es aprender cuáles cosas podemos cambiar y entonces dedicarnos a hacer eso.

- Recuerde que el tiempo está de su lado

El tiempo cura muchas heridas. Esto no significa que el vivir con un niño que tiene problemas, y criarlo, será fácil, pero es justo decir que, a medida que el tiempo pasa, mucho puede ser hecho para aliviar el problema. Por lo tanto, iel tiempo ayuda!

- Encuentre programas para su niño

Aún para aquellos que viven en zonas alejadas del país, la asistencia está disponible para ayudarle con cualquier clase de problema que usted esté teniendo. Mientras trata de encontrar programas para su niño con una discapacidad, mantenga en mente que también hay programas disponibles para el resto de la familia.

\section{- Tome cuidado de sí mismo}

En tiempos de tensión, cada persona reacciona de manera diferente. Unas cuantas recomendaciones universales pueden ayudar: tenga descanso suficiente; coma lo mejor que pueda; reserve tiempo para usted mismo; busque el apoyo emocional de otros. 


\section{- Evite la compasión}

Tener compasión de sí mismo, experimentar compasión con otros, o sentir compasión por su niño son actos que incapacitan. Compasión es lo que no se necesita. Simpatía, lo cual es la habilidad de sentir afecto por otra persona, es la actitud que debe ser alentada.

\section{- Decida cómo tratar con otros}

Durante este periodo, puede sentirse entristecido o enojado acerca de la forma como la gente está reaccionando hacia usted o hacia su niño. Muchas reacciones de la gente hacia problemas serios son causadas por la falta de entendimiento, simplemente no sabiendo qué decir o por miedo a lo desconocido. Entienda que mucha gente no sabe cómo comportarse cuando ven un niño con discapacidad y ellos pueden reaccionar inapropiadamente. Piense acerca de ello y decida cómo quiere usted tratar con las miradas fijas o las preguntas de la gente. Trate de no usar mucha energía estando preocupado acerca de las personas que no son capaces de responder en las formas que usted pudiera preferir.

- Mantenga las rutinas diarias tan normales como le sea posible

Una vez mi madre me dijo, Cuando se presente un problema y no sepas qué hacer, entonces haz de todos modos lo que tengas que hacer. Practicar este hábito parece producir alguna normalidad y consistencia cuando la vida llega a ser febril.

\section{- Recuerde que este es su niño}

Esta persona es, primero y sobre todo, su niño. Dé por sentado que el desarrollo de su niño puede ser diferente al de otros niños, pero esto no hace a su niño menos valioso, menos humano, menos importante, o con menor necesidad de su amor y crianza. Ame y goce su niño. El niño viene en primer lugar, la discapacidad en segundo. Si usted puede descansar y seguir las etapas positivas aquí descritas, una sola a la vez, hará lo mejor que pueda, su hijo se beneficiará, y podrá mirar hacia el futuro con esperanza.

- Reconozca que Ud. no está solo

El sentimiento de aislamiento al momento del diagnóstico es casi universal entre los padres. En éste artículo, hay muchas recomendaciones para ayudarle a manejar los sentimientos de aislamiento y separación. Ayuda saber que estos sentimientos han sido experimentados por muchos, muchos otros, que hay disponible comprensión y ayuda constructiva para usted y para su niño, y recuerde siempre que usted no está solo. 


\section{Padres y maestras trabajando juntos}

Los maestros y los padres de familia trabajando juntos pueden lograr grandes beneficios en favor de los niños discapacitados.

Se aspira que en el futuro la intervención del hogar no se limite a la relación entre padres e hijos sino también abarque las relaciones entre los miembros de la familia.

La relación familia-escuela, podrá establecerse cuando los dos ambientes se expresen en el mismo lenguaje, tengan los mismos intereses y vayan al mismo punto, exista credibilidad y confianza mutua y una estructura de relación abierta, flexible y directa que permita adecuar tanto a la familia como a la escuela a la realidad del niño con necesidades educativas especiales.

Los padres y maestros que colaboran unos con otros en forma activa y eficaz forman un equipo poderoso. "La familia del estudiante con N.E.E. o quien haga sus veces, tienen un rol activo y comprometido en la decisión de escolarización en el desarrollo del proceso educativo y en las medidas y apoyos complementarios que garanticen un servicio educativo pertinente a las necesidades y potencialidades de los hijos" (Reglamento educación básica especial. Art. № 25.: del 12/0I/05).

La relación entre padres y profesores proporciona a estos:

- Una mayor comprensión de las necesidades generales del niño y de las necesidades y deseos del padre.

- Información para una selección más significativa de las conductas de estos niños.

- Acceso a una amplia variedad de refuerzos sociales y actividades, proporcionados por los padres.

- Mayores oportunidades de reforzar las conductas adecuadas, tanto en la escuela como en el hogar.

- Información por parte de los padres acerca de los cambios de conducta de los niños, que pueden ser utilizados para perfeccionar los programas que aplican los profesores y los padres.

- La posibilidad de cumplir las leyes que exigen la continua colaboración de los padres en el proceso educativo.

\section{La relación entre padres y profesores proporciona a los padres:}

- Una mayor comprensión de las necesidades de sus hijos y de los objetivos del maestro.

- Información referente a los derechos y responsabilidades como padres de un 
niño con necesidades educativas especiales.

- Información específica acerca del programa escolar de su hijo y de qué manera pueden participar.

- Modos específicos de extender los efectos positivos de la programación escolar al hogar.

- Mayores aptitudes para ayudar a su hijo a aprender conductas funcionales que sean apropiadas para el hogar.

- Acceso a más recursos importantes (actuales y futuros para su hijo).

\section{Lo que es de mayor importancia, es que esta relación entre padres y maestros proporciona al niño:}

- Una mayor coherencia en sus dos ámbitos más importantes.

- Mayores oportunidades de aprendizaje y crecimiento.

- Acceso a mayores recursos y servicios.

En nuestra realidad el SAANEE (Servicios de Apoyo y Asesoramiento a estudiantes con Necesidades Educativas Especiales. Ministerio de Educación 2006, pp. 41-42) es el encargado de orientar, asesorar y capacitar a la familia del estudiante con necesidades educativas especiales o a quien gaga sus veces, en coordinación con el docente inclusivo y para que tenga un rol activo y comprometido en la escolarización, en el desarrollo del proceso educativo y en los apoyos complementarios.

EI SAANEE debe tener en cuenta, para operativizar el trabajo con familias, la búsqueda constante de estrategias en relación con la discapacidad y mejorar su desempeño.

Los padres son los adultos más importantes en la vida de un niño. Un buen maestro debe ser el segundo adulto más importante en la vida del niño. De allí que, trabajando juntos de manera armónica podremos desarrollar aquellas habilidades ocultas, aquello que puede hacer y que tiene todo niño y en esta forma estaremos asegurando la igualdad de oportunidades para su desarrollo integral, adecuado y a su participación activa en la sociedad. a lo que tiene derecho toda persona. 